\title{
Home Remodeling and Food Allergy Interact Synergistically to Increase the Risk of Atopic Dermatitis
}

\author{
Won Seok Lee, ${ }^{1}$ Kyung Suk Lee, ${ }^{2}$ Shinhae Lee, ${ }^{2}$ Myongsoon Sung, ${ }^{3}$ Seung-Jin Lee, ${ }^{2}$ \\ Hye Mi Jee, ${ }^{2}$ Youn Ho Sheen, ${ }^{4}$ Man Yong Han, ${ }^{2}$ and Young-Ho Jung ${ }^{2}$ \\ ${ }^{1}$ Department of Pediatrics, Graduate School, Kyung Hee University, Seoul, Republic of Korea \\ ${ }^{2}$ Department of Pediatrics, CHA Bundang Medical Center, CHA University School of Medicine, Seongnam, Republic of Korea \\ ${ }^{3}$ Department of Pediatrics, Haeundae Paik Hospital, Inje University School of Medicine, Busan, Republic of Korea \\ ${ }^{4}$ Department of Pediatrics, CHA Gangnam Medical Center, CHA University School of Medicine, Seoul, Republic of Korea
}

Correspondence should be addressed to Young-Ho Jung; younghojung97@gmail.com

Received 18 April 2017; Accepted 13 August 2017; Published 20 September 2017

Academic Editor: Marzia Caproni

Copyright (C) 2017 Won Seok Lee et al. This is an open access article distributed under the Creative Commons Attribution License, which permits unrestricted use, distribution, and reproduction in any medium, provided the original work is properly cited.

\begin{abstract}
Purpose. The purpose of this study was to investigate the effects of home remodeling and food allergy (FA) on the development of atopic dermatitis (AD) in children. Methods. The Modified International Study of Asthma and Allergies in Childhood questionnaire was used to survey 4,111 children recruited from 3 kindergartens and 6 elementary schools from Seongnam, Korea. Participants' parents agreed for them to participate in physical examinations, skin prick tests, and blood tests. Results. Home remodeling in the past 12 months (adjusted odds ratio [aOR] 3.40, $P=0.006$ ), lifetime diagnosis of FA (aOR 3.95, $P<0.001$ ), parental history of $\mathrm{AD}(\mathrm{aOR} 2.67, P=0.001$ ), and FA (aOR 2.35, $P=0.004$ ) were independent risk factors for lifetime diagnosis of $\mathrm{AD}$ ever. When history of home remodeling and FA were combined, the risk for moderate-to-severe AD by scoring atopic dermatitis (SCORAD) score increased $(\mathrm{aOR}, 7.19, P=0.011, P$ for interaction $=0.034)$. Conclusion. Home remodeling, lifetime diagnosis of FA, parental history of $\mathrm{AD}$, and parental history of FA were independent risk factors for $\mathrm{AD}$. In addition, we observed a synergistic interaction between home remodeling and FA in the risk of moderate-to-severe AD.
\end{abstract}

\section{Introduction}

Atopic dermatitis (AD) typically arises at an early age and is the most common chronic, relapsing, inflammatory eczematous skin disease [1]. The pathogenesis of AD is complex with multifactorial etiologies involving genetic, immunological, and environmental factors. The prevalence of $\mathrm{AD}$ has risen globally in recent years [1]. There are several reasons for this trend, including genetic factors and increasing prevalence of food allergy (FA) [2,3]. Recently, environmental factors involving air pollution have been considered as a newly emerging cause for the increased prevalence of $\mathrm{AD}$ [2].

Indoor air pollution is an important environmental factor for children, as they tend to spend most of their daytime indoors [4]. Materials affecting outdoor air include particulate matter $<10 \mathrm{~mm}\left(\mathrm{PM}_{10}\right)$, nitrogen oxides $\left(\mathrm{NO}_{x}\right)$, sulfur oxides $\left(\mathrm{SO}_{x}\right)$, and ozone $\left(\mathrm{O}_{3}\right)$ [5]. Materials with substantial effect on indoor air pollution are different from outdoor materials [4]. The causative materials of indoor air pollution include wallpaper, flooring, and paint [6]. Formaldehyde, volatile organic compounds (VOCs), and aromatic compounds are pollutants that are considered more important than other indoor chemicals [7]. Mendell reported that indoor pollutants may play a key role in the development and aggravation of allergic diseases such as $\mathrm{AD}$ [4]. High concentrations of VOCs or formaldehyde are associated with the development of Sick Building Syndrome (SBS) and the aggravation of allergic diseases in newly built dwellings [8]. In one study, authors have shown that exposure to home renovation was associated with a higher risk of allergic diseases in children [9]. Therefore, it can be inferred that these changes to the indoor environment may play a considerable role in increasing the incidence of $\mathrm{AD}$.

FA is defined as adverse health reactions to foods consisting of any unanticipated reactions following the ingestion of 
foods or food additives [10]. Previously published literature indicated that FA plays an important role in exacerbating severe forms of AD [11]. Approximately one-third of children with severe $\mathrm{AD}$ have also been reported to have IgE mediated FA [12].

Based on these data, we hypothesized that home remodeling and FA may be linked with the development of AD. However, there have been no studies determining that home remodeling and FA together are risk factors for AD in Korea. We sought to examine the effects of home remodeling and $\mathrm{FA}$ on the development of $\mathrm{AD}$ in children and determine how they contribute synergistically to the occurrence of this disease.

\section{Materials and Methods}

2.1. Subjects. This cross-sectional study was based on a population of 5,196 children aged 4-13 years who attended 3 kindergartens and 6 elementary schools in Seongnam, Korea, between June and July, 2015. Of these subjects, 4,111 completed the questionnaire (response rate, 79.1\%) [13]. The participants' parents provided consented for their children to participate in a physical examination, skin prick tests (SPTs), and blood sampling. Pediatricians and trained field technicians conducted the physical examinations, SPTs, and blood sampling at the participating schools. Data pertaining parental economic status were collected and converted to US dollars using an exchange rate of US $\$ 1=1112.40$ South Korean won (exchange rate at June, 1, 2015) [14]. Characteristics of the subjects are described in Table 1 .

This study was approved by the Institutional Review Board of the CHA Bundang Medical Center. Written consent was obtained from all parents or guardians following a detailed explanation.

2.2. Modified International Study of Asthma and Allergies in Childhood Questionnaire. A modified Korean version of the International Study of Asthma and Allergies in Childhood (ISAAC) questionnaire was used to determine the prevalence of symptoms and diagnosis of allergic diseases [13]. The questionnaire was consisted of three main sections: (1) general characteristics including sex, date of birth, height, and weight; (2) a history of symptoms related to asthma, allergic rhinitis (AR), AD, and FA; and (3) exposure to environmental factors, including home remodeling.

A child was deemed to have been diagnosed with AD and FA or to have a history of home remodeling if an affirmative answer was given to questions "has your child ever been diagnosed with AD by a physician?," "has your child ever been diagnosed with FA by a physician?," and "have you ever done home remodeling?," respectively.

2.3. Scoring Atopic Dermatitis Index. Three pediatricians (Dr. Jee, Dr. Jung, and Dr. Lee) visited each school and calculated the scoring atopic dermatitis (SCORAD) scores of each participant in an enclosed space at their respective school. The AD group was divided into three classes based on the severity of AD: mild $(<25)$, moderate $(25-50)$, and severe $(>50)[15]$.
TABLE 1: Demographic and clinical characteristics of subjects.

\begin{tabular}{lc}
\hline Characteristics & \\
\hline Number & 4,111 \\
Age (years), mean \pm SD & $8.00 \pm 1.85$ \\
Sex (Boy: Girl) & $2,121: 1,980(51.7 \%: 48.3 \%)$ \\
BMI & $17.44 \pm 2.83$ \\
Parental history of allergic diseases & $2,312 / 4,111(56.2 \%)$ \\
$\quad$ Parental history of asthma & $203 / 4,111(4.9 \%)$ \\
Parental history of allergic rhinitis & $2,075 / 4,111(50.5 \%)$ \\
Parental history of AD & $400 / 4,111(9.7 \%)$ \\
$\quad$ Parental history of FA & $346 / 4,111(8.4 \%)$ \\
Environmental tobacco smoking & $1,475 / 4,041(36.5 \%)$ \\
Lifetime home remodeling & $1,146 / 4,014(28.6 \%)$ \\
Moving to new home in infancy & $1,054 / 3,299(31.9 \%)$ \\
Educational degree of mother & \\
$\quad \leq$ High school graduate & $795 / 3,984(20.0 \%)$ \\
$\quad \geq$ University graduate & $3,189 / 3,984(80.0 \%)$ \\
Parental economic status (monthly income) & \\
Low (<2,697 USD) & $439 / 3,860(11.4 \%)$ \\
Middle (2,697-5,393 USD) & $1,700 / 3,860(44.0 \%)$ \\
High ( $\geq 5,393$ USD) & $1,721 / 3,860(44.6 \%)$ \\
Biomarkers & \\
Eosinophil (\%), mean \pm SD & $3.85 \pm 2.97$ \\
Atopy & $297 / 575(51.7 \%)$ \\
\hline SD standard devion; BMI: &
\end{tabular}

SD: standard deviation; BMI: body mass index; AD: atopic dermatitis; FA: food allergy; USD: United States of America dollar. ${ }^{*}$ Defined as at least 1 positive skin prick test (allergen and histamine wheal diameter $>3 \mathrm{~mm}$ ).

2.4. Skin Prick Test and Laboratory Test. SPTs were performed on the volar surface of the skin of the arm with normal appearance using standardized allergen extracts and control solutions from Laforma (Milan, Italy). Subjects were tested for sensitivity to the following 22 common allergens: Dermatophagoides pteronyssinus (D.p.), Dermatophagoides farinae (D.f.), birch, oak, walnut, apple, peach, kiwi, egg, milk, cod, pork, elm, hops, peanut, wheat, orange, tomato, strawberry, celery, mussel, and shrimp. Subjects were deemed to be atopic if they tested positive to one or more allergen in the SPTs (allergen and histamine wheal diameter $>3 \mathrm{~mm}$ ) [16]. White blood cell counts were measured, and the percentage of blood eosinophils was calculated.

2.5. Statistical Analysis. Statistical analyses were performed using SPSS version 23.0 (IBM Co., Armonk, NY, USA). Prevalence was presented in 95\% confidence intervals (CIs). Logistic regression analyses were conducted to identify independent risk factors for AD. Multivariate analysis was adjusted for personal, familial, and socioeconomic factors. To test the interaction effect between environments (home remodeling and FA history) on $\mathrm{AD}$, logistic regression analysis between home remodeling and FA history on $\mathrm{AD}$ was performed. For all analyses (two-tailed), $P<0.05$ was considered to indicate statistical significance. 


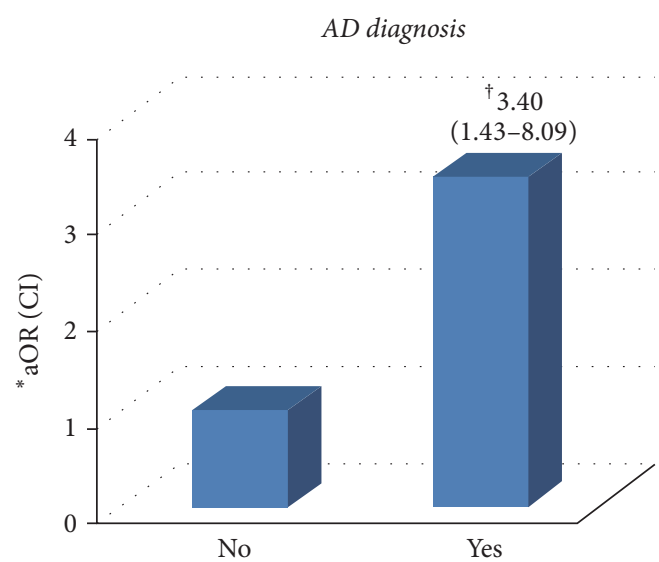

(a)

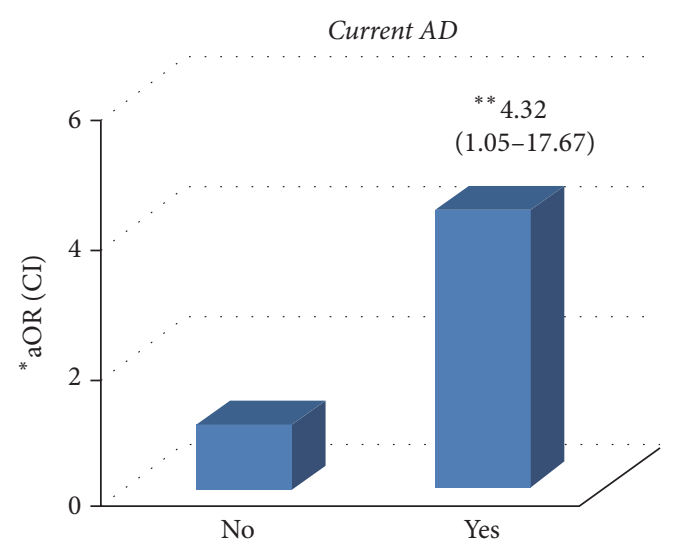

(b)

FIGURE 1: Home remodeling within recent 1 year as a risk factor of lifetime diagnosis of $\operatorname{AD}(N=123)$ and current $\mathrm{AD}(N=100)$. (a) Home remodeling in the past 12 months is a risk factor of lifetime diagnosis of $\mathrm{AD}\left({ }^{\dagger} \mathrm{aOR} 3.40,95 \% \mathrm{CI} 1.43-8.09, P=0.006\right)$. (b) Home remodeling in the past 12 months is a risk factor of current $\mathrm{AD}\left({ }^{* *} \mathrm{aOR} 4.32,95 \% \mathrm{CI} 1.05-17.67, P=0.042\right)$. The data was calculated by logistic regression multivariate analysis. aOR: adjusted odds ratio; CI: confidence interval; BMI: body mass index; AD: atopic dermatitis. ${ }^{*}$ aOR was adjusted by age, sex, $\mathrm{BMI}$, parental history of $\mathrm{AD}$, familial income, and eosinophil.

TABle 2: Prevalence of AD.

\begin{tabular}{lcc}
\hline & Number & Prevalence, $\%$ \\
\hline Lifetime symptoms & $775 / 4,111$ & 18.9 \\
Symptoms in the past 12 months & $588 / 4,111$ & 14.3 \\
Lifetime diagnosis & $1,240 / 4,111$ & 30.2 \\
Treatment in the past 12 months & $403 / 4,111$ & 9.8 \\
Current AD* & $483 / 4,111$ & 11.7 \\
Moderate-to-severe $\mathrm{AD}^{\dagger}$ & $38 / 578$ & 6.6 \\
\hline
\end{tabular}

AD: atopic dermatitis; SCORAD: scoring atopic dermatitis. ${ }^{*}$ Defined as lifetime diagnosis together with symptoms in the past 12 months in the questionnaire; ${ }^{\dagger} 578$ participated in SCORAD testing. Moderate-to-severe $\mathrm{AD}$ was defined as a SCORAD score $>25$.

\section{Results}

3.1. Subject Characteristics. The children were aged $8.00 \pm 1.85$ years. The majority of the participants were boys (51.7\%) and approximately $56 \%$ of the participants had a parental history of allergic diseases, including asthma, $\mathrm{AR}, \mathrm{AD}$, and FA (Table 1).

3.2. Prevalence of $A D$. AD-related prevalence is listed in Table 2. Current AD, defined as lifetime diagnosis together with the presence of symptoms in the past 12 months in the questionnaire, was $11.7 \%$. Moderate-to-severe AD (SCORAD score $>25$ ) was $6.6 \%$.

3.3. Risk Factors for Lifetime Diagnosis of $A D$. Independent risk factors for lifetime diagnosis of $\mathrm{AD}$ were: girl (aOR 1.69, $P=0.016)$, lifetime diagnosis of FA (aOR 3.95, $P<0.001$ ), lifetime diagnosis of asthma (aOR 3.38, $P<0.001)$, lifetime diagnosis of AR (aOR 2.37, $P<0.001$ ), parental history of allergic diseases (aOR 3.22, $P<0.001$ ), parental history of $\mathrm{AD}(\mathrm{aOR} 2.67, P=0.001)$, and home remodeling in the past 12 months (aOR 3.40, $P=0.006$ ) (Table 3 ).
3.4. Home Remodeling Increases the Risk of AD. Children with a home remodeling history in the past 12 months had an increased risk for lifetime diagnosis of $\mathrm{AD}(\mathrm{aOR}=3.40$, $P=0.006$ ) (Figure 1(a)). Children with a home remodeling history in the past 12 months had increased risk for current $\mathrm{AD}(\mathrm{aOR}=4.32, P=0.042)($ Figure $1(\mathrm{~b}))$.

3.5. Home Remodeling and FA History Act Synergistically to Increase Risk of Moderate-to-Severe AD. Children were divided into four groups based on their history of home remodeling within 12 months and FA. When home remodeling and FA variable were combined, the risk for moderateto-severe $\mathrm{AD}$ incidence was significantly increased $(\mathrm{aOR}=$ $7.19, P=0.011, P$ for interaction $=0.034)($ Figure 2$)$.

\section{Discussion}

The purpose of this cross-sectional study was to investigate how home remodeling and FA may be associated with $\mathrm{AD}$ in children and how they interact with each other with regard to AD. In this study, overall lifetime diagnosis of $\mathrm{AD}$ was $30.2 \%$, and several independent risk factors were identified that increased the risk for $\mathrm{AD}$. When lifetime diagnosis of home remodeling and FA were combined, the risk for moderate-tosevere AD significantly increased. Home remodeling history in the past 12 months was also an independent risk factor for current $\mathrm{AD}$.

Housing reconstruction and remodeling activities have rapidly developed in the past several decades in Korea [17]. Many people previously lived in private houses, but during the past several years, they have gradually moved to community housing, such as apartments [17]. Nuclear families have become more common, and married young couples often move to newly built apartments or remodeled houses [17].

A variety of materials are used for reconstruction and house remodeling, including organic solvents, heavy metals, 
TABLE 3: Risk factors for lifetime diagnosis of AD.

\begin{tabular}{|c|c|c|}
\hline \multirow{3}{*}{ Risk factors } & \multicolumn{2}{|c|}{$N(\%)$} \\
\hline & \multicolumn{2}{|c|}{$435 / 4,111(10.6 \%)$} \\
\hline & $\mathrm{aOR}^{*}(95 \% \mathrm{CI})$ & $P$ value \\
\hline \multicolumn{3}{|l|}{ Demographic factors } \\
\hline Age (older) & $0.96(0.85-1.07)$ & 0.431 \\
\hline Sex (girl) & $1.69(1.10-2.58)$ & 0.016 \\
\hline BMI & $1.03(0.95-1.11)$ & 0.514 \\
\hline Educational status of the mother ( $\geq$ university graduate) & $1.61(0.99-2.62)$ & 0.053 \\
\hline Economic status (higher monthly income) & $1.12(0.84-1.48)$ & 0.436 \\
\hline \multicolumn{3}{|l|}{ Personal factors } \\
\hline Lifetime diagnosis of FA & $3.95(2.00-7.83)$ & $<0.001$ \\
\hline Lifetime diagnosis of asthma & $3.38(1.72-6.67)$ & $<0.001$ \\
\hline Lifetime diagnosis of allergic rhinitis & $2.37(1.57-3.60)$ & $<0.001$ \\
\hline Breast milk feeding & $1.55(0.94-2.58)$ & 0.089 \\
\hline Premature birth & $1.86(0.89-3.91)$ & 0.101 \\
\hline Delivery (Cesarean section) & $0.96(0.63-1.46)$ & 0.858 \\
\hline \multicolumn{3}{|l|}{ Genetic factors } \\
\hline Parental history of allergic diseases & $3.22^{\dagger}(2.04-5.10)$ & $<0.001$ \\
\hline Parental history of $\mathrm{AD}$ & $2.67^{\dagger}(1.47-4.83)$ & 0.001 \\
\hline Parental history of asthma & $2.16(0.90-5.21)$ & 0.087 \\
\hline Parental history of allergic rhinitis & $2.46(1.60-3.79)$ & $<0.001$ \\
\hline Parental history of FA & $2.35(1.31-4.24)$ & 0.004 \\
\hline \multicolumn{3}{|l|}{ Environmental factors } \\
\hline Dog ownership & $0.61(0.18-2.10)$ & 0.432 \\
\hline Cat ownership & $1.48(0.23-9.51)$ & 0.681 \\
\hline Day care attendance before 1 year old & $0.66(0.18-2.39)$ & 0.523 \\
\hline Older siblings & $0.76(0.51-1.13)$ & 0.174 \\
\hline Home remodeling, ever & $1.37(0.89-2.12)$ & 0.151 \\
\hline Home remodeling in infancy & $0.86(0.16-4.78)$ & 0.864 \\
\hline Home remodeling in the past 12 months & $3.40(1.43-8.09)$ & 0.006 \\
\hline Moving to new home in infancy & $0.98(0.62-1.56)$ & 0.944 \\
\hline \multicolumn{3}{|l|}{ Biomarkers } \\
\hline Eosinophil $>4 \%$ & $2.37^{* *}(1.54-3.62)$ & $<0.001$ \\
\hline Eosinophil 4th quartile (>5.0\%) & $2.49^{* *}(1.57-3.94)$ & $<0.001$ \\
\hline
\end{tabular}

The data were calculated by logistic regression multivariate analysis. aOR: adjusted odds ratio; CI: confidence interval; BMI: body mass index; FA: food allergy; $\mathrm{AD}$ : atopic dermatitis. ${ }^{*} \mathrm{aOR}$ was adjusted by age, sex, BMI, parental history of $\mathrm{AD}$, familial income, and eosinophil. ${ }^{\dagger}$ aOR was adjusted by age, sex, BMI, familial income, and eosinophil. ${ }^{* *}$ aOR was adjusted by age, sex, BMI, parental history of AD, and familial income. Significant aOR and $P$ values are in bold.

and VOCs, such as benzene, toluene, xylene, styrene, and formaldehyde, may be emitted from paints or dyes [4]. VOCs can damage the epidermal barrier and increase the adverse effects of house dust mites on sensitized subjects with AD [18]. Only short-term exposure to formaldehyde can cause dysfunction of the skin barrier in children with and without $\mathrm{AD}$; this is more prominent in the latter [19]. In an experimental rat model of $\mathrm{AD}$, exposure to formaldehyde aggravated pruritus and dermatitis and was associated with an elevated expression of Th1 cytokines [20]. Exposure to nitrogen dioxide $\left(\mathrm{NO}_{2}\right)$ at domestic concentrations causes impairment of the skin barrier function in subjects with $\mathrm{AD}$ [21]. Airborne particulate matter (PM) has also been identified as a risk factor for deteriorating skin condition in patients with $\mathrm{AD}$ [22]. These findings suggest that indoor air pollutants play a key role in the development and aggravation of allergic diseases such as AD [4].

To understand how home remodeling and FA may be synergistically related to $\mathrm{AD}$, it is important to understand their relationship. Patients with $\mathrm{AD}$ are known to have other atopic diseases, such as IgE mediated food allergy [11]. Böhme et al. reported that $27 \%$ of patients with $\mathrm{AD}$ patients were sensitized to food allergens at 2 years of age, including egg $(21 \%)$, peanuts $(15 \%)$, milk ( $8 \%)$, and cod positive $(2 \%)$ [23]. In a study performed in the United Kingdom $(N=$ 1,402 children), egg sensitization on SPT was significantly associated with AD (OR 9.53, 95\% CI 2.40-37.82, $P<$ 0.05) [24]. Researchers also described that the process of recognition of food allergens through antigen-presenting 


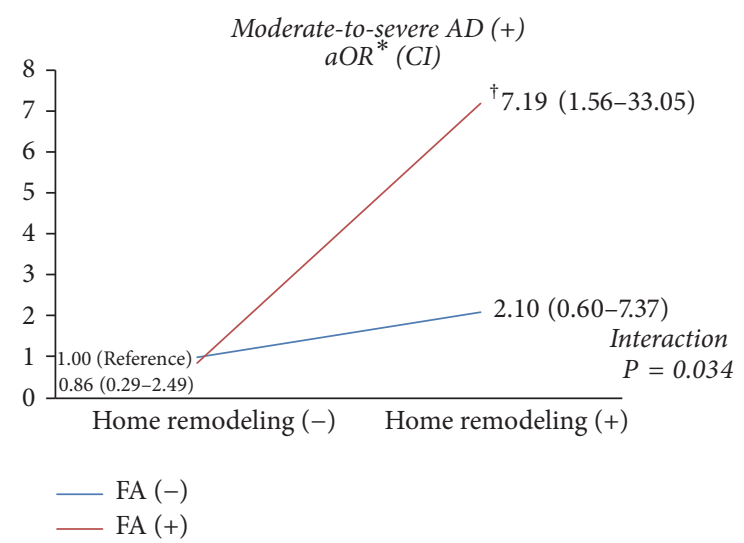

FIGURE 2: Effect of home remodeling on the risk of moderate-tosevere AD by SCORAD score in children with and without FA history $(N=421)$. When home remodeling and FA variable were combined, the risk for moderate-to-severe $\mathrm{AD}$ incidence was significantly increased. (aOR 7.19, 95\% CI $1.56-33.05,{ }^{\dagger} P=0.011$, $P$ for interaction $=0.034)$. The data was calculated by logistic regression multivariate analysis. aOR: adjusted odds ratio; CI: confidence interval; BMI: body mass index; $\mathrm{AD}$ : atopic dermatitis; SCORAD: scoring atopic dermatitis; FA: food allergy. ${ }^{*}$ aOR was adjusted by age, sex, $\mathrm{BMI}$, parental history of $\mathrm{AD}$, familial income, and eosinophil.

cells in the eczematous skin may serve as an important mediator of food sensitization and FA [25].

Researchers have demonstrated that the development of FA due to exposure to indoor pollutants may be related to home remodeling $[26,27]$. Shiue found that urinary arsenic, heavy metal, and phthalate concentrations are associated with peanut, egg, milk, and shrimp sensitizations [26]. Stelmach et al. reported that maternal exposure to phthalate during pregnancy increased the risk for FA [27].

Several studies have provided helpful information related to the synergistic effect of FA and home remodeling on the prevalence of $\mathrm{AD}[28,29]$. In particular, filaggrin (FLG) is an important protein in the skin and plays an important role in maintaining the integrity of the skin barrier [28]. FLG is associated with increased FA and several diseases with barrier dysfunction, such as ichthyosis vulgaris and $\mathrm{AD}$ [28]. In one study of patients with $\mathrm{AD}$ and the FLG gene variant, the higher skin permeability allowed the absorption of phthalate through the skin, resulting in higher urine phthalate metabolite levels than the control group [29]. This weakened skin barrier may lead to an increased absorption of indoor pollutants, such as phthalate, through the skin, aggravating eczematous skin lesions [29].

Efforts are needed to decrease the prevalence of $\mathrm{AD}$ related to home remodeling or reduce symptomatic deterioration in patients with AD. The common and basic way to improve indoor air quality is frequent cleaning, vacuuming, and ventilation [30]. The use of environmentally friendly materials in wallpaper and flooring should also be considered [6]. Lee et al. reported that there is a close relationship between the construction year of the house or moving to a newly constructed building within 1 year and formaldehyde level [31].

We acknowledge that this study has several limitations. We used a cross-sectional study design and gathered data via a questionnaire; therefore, we cannot infer a causal relationship. There is also the possibility of biases due to the methodology used. However, we conducted this study in a regional area intentionally and analyzed questionnaires and laboratory findings to reveal, for the first time in a Korean population, the relationship between allergic diseases and indoor pollution. Therefore, our study may be used as a representative study to increase awareness of the seriousness of indoor pollution among Korean children. Cohort studies are needed to confirm our findings.

Altogether, we found that home remodeling and FA history are independent risk factors for $\mathrm{AD}$ in children. We also observed a synergistic effect between home remodeling and FA in increasing the risk for moderate-to-severe AD. To prevent and manage the development of $\mathrm{AD}$, further studies are needed to clarify how indoor pollutants interact with food allergens in the development of $\mathrm{AD}$ with more objective measures, including urine and blood samples, as well as measurements of the concentration of indoor air pollutants.

\section{Conflicts of Interest}

There are no conflicts of interest to declare.

\section{Authors' Contributions}

Won Seok Lee and Kyung Suk Lee contributed equally as cofirst authors to this study.

\section{Acknowledgments}

This study was supported by the 2015 Seongnam Atopy Project grant provided by Seongnam-si, Gyeonggi-do, Korea.

\section{References}

[1] H. Chu, J. U. Shin, C. O. Park, H. Lee, J. Lee, and K. H. Lee, "Clinical diversity of atopic dermatitis: A review of 5,000 patients at a single institute," Allergy, Asthma and Immunology Research, vol. 9, no. 2, pp. 158-168, 2017.

[2] H. Williams, A. Stewart, E. von Mutius, W. Cookson, and H. R. Anderson, "Is eczema really on the increase worldwide?" Journal of Allergy and Clinical Immunology, vol. 121, no. 4, pp. 947-e15, 2008.

[3] R. A. Wood, "Advances in food allergy in 2015," Journal of Allergy and Clinical Immunology, vol. 138, no. 6, pp. 1541-1547, 2016.

[4] M. J. Mendell, "Indoor residential chemical emissions as risk factors for respiratory and allergic effects in children: A review," Indoor Air, vol. 17, no. 4, pp. 259-277, 2007.

[5] J. Schwartz, "Air pollution and children's health," Pediatrics, vol. 113, no. 4, supplement, pp. 1037-1043, 2004.

[6] J. I. Na, S. Y. Byun, M. Y. Jeong, K. C. Park, and C. H. Huh, "The effect of environmentally friendly wallpaper and flooring 
material on indoor air quality and atopic dermatitis: a pilot study," Annals of Dermatology, vol. 26, no. 6, pp. 688-692, 2014.

[7] J. Kim, H. Kim, D. Lim, Y.-K. Lee, and J. H. Kim, "Effects of indoor air pollutants on atopic dermatitis," International Journal of Environmental Research and Public Health, vol. 13, no. 12, article no. 1220, 2016.

[8] B.-L. Wang, T. Takigawa, Y. Yamasaki, N. Sakano, D.-H. Wang, and K. Ogino, "Symptom definitions for SBS (sick building syndrome) in residential dwellings," International Journal of Hygiene and Environmental Health, vol. 211, no. 1-2, pp. 114-120, 2008.

[9] J. Yu, K. Ahn, Y. H. Shin et al., "The interaction between prenatal exposure to home renovation and reactive oxygen species genes in cord blood IgE response is modified by maternal atopy," Allergy, Asthma \& Immunology Research, vol. 8, no. 1, pp. 41-48, 2016.

[10] J. A. Boyce, A. Assa'ad, A. W. Burks et al., "Guidelines for the diagnosis and management of food allergy in the united states: summary of the NIAID-sponsored expert panel report," Journal of Allergy and Clinical Immunology, vol. 126, no. 6, pp. 1105-1118, 2010.

[11] T. Werfel, B. Ballmer-Weber, P. A. Eigenmann et al., "Eczematous reactions to food in atopic eczema: Position paper of the EAACI and GA2LEN," Allergy: European Journal of Allergy and Clinical Immunology, vol. 62, no. 7, pp. 723-728, 2007.

[12] J. Celakovská and J. Bukac, "Analysis of food allergy in atopic dermatitis patients-association with concomitant allergic diseases," Indian Journal of Dermatology, vol. 59, no. 5, pp. 445-450, 2014.

[13] S. J. Lee, E. K. Ha, H. M. Jee et al., "Prevalence and risk factors of urticaria with a focus on chronic urticaria in children," Allergy, Asthma and Immunology Research, vol. 9, no. 3, pp. 212-219, 2017.

[14] K. E. Bank, The exchange rate at June 2015, https://www .kebhana.com/.

[15] A. P. Oranje, E. J. Glazenburg, A. Wolkerstorfer, and F. B. De Waard-Van Der Spek, "Practical issues on interpretation of scoring atopic dermatitis: the SCORAD index, objective SCORAD and the three-item severity score," British Journal of Dermatology, vol. 157, no. 4, pp. 645-648, 2007.

[16] R. G. Hamilton, "Clinical laboratory assessment of immediatetype hypersensitivity," Journal of Allergy and Clinical Immunology, vol. 125, no. 2, supplement 2, pp. S284-S296, 2010.

[17] S. K. Ha, "Urban growth and housing development in Korea: a critical overview," Korea Journal, vol. 39, no. 3, pp. 63-95, 1999.

[18] J. Huss-Marp, B. Eberlein-König, K. Breuer et al., "Influence of short-term exposure to airborne Der p 1 and volatile organic compounds on skin barrier function and dermal blood flow in patients with atopic eczema and healthy individuals," Clinical and Experimental Allergy, vol. 36, no. 3, pp. 338-345, 2006.

[19] J. Kim, Y. Han, J. H. Ahn et al., "Airborne formaldehyde causes skin barrier dysfunction in atopic dermatitis," British Journal of Dermatology, vol. 175, no. 2, pp. 357-363, 2016.

[20] R. T. Han, S. K. Back, H. Lee et al., "Formaldehyde-induced aggravation of pruritus and dermatitis is associated with the elevated expression of Thl cytokines in a rat model of atopic dermatitis," PLoS ONE, vol. 11, no. 12, Article ID e0168466, 2016.

[21] B. Eberlein-König, B. Przybilla, P. Kühnl et al., "Influence of airborne nitrogen dioxide or formaldehyde on parameters of skin function and cellular activation in patients with atopic eczema and control subjects," Journal of Allergy and Clinical Immunology, vol. 101, no. 1, pp. 141-143, 1998.
[22] K.-L. E. Hon, T.-F. Leung, G. Ching et al., "Patterns of food and aeroallergen sensitization in childhood eczema," Acta Paediatrica, International Journal of Paediatrics, vol. 97, no. 12, pp. 1734-1737, 2008.

[23] M. Böhme, Å. Svensson, I. Kull, S. L. Nordvall, and C.-F. Wahlgren, "Clinical features of atopic dermatitis at two years of age: a pospective, population-based case-control study," Acta Dermato-Venereologica, vol. 81, no. 3, pp. 193-197, 2001.

[24] D. G. Peroni, G. L. Piacentini, A. Bodini, E. Rigotti, R. Pigozzi, and A. L. Boner, "Prevalence and risk factors for atopic dermatitis in preschool children," British Journal of Dermatology, vol. 158, no. 3, pp. 539-543, 2008.

[25] C. Flohr, M. Perkin, K. Logan et al., "Atopic dermatitis and disease severity are the main risk factors for food sensitization in exclusively breastfed infants," Journal of Investigative Dermatology, vol. 134, no. 2, pp. 345-350, 2014.

[26] I. Shiue, "Association of urinary arsenic, heavy metal, and phthalate concentrations with food allergy in adults: National Health and Nutrition Examination Survey, 2005-2006," Annals of Allergy, Asthma and Immunology, vol. 111, no. 5, pp. 421-423, 2013.

[27] I. Stelmach, P. Majak, J. Jerzynska et al., "The effect of prenatal exposure to phthalates on food allergy and early eczema in inner-city children," Allergy and Asthma Proceedings, vol. 36, no. 4, pp. e72-e78, 2015.

[28] A. D. Irvine, W. H. I. McLean, and D. Y. M. Leung, "Filaggrin mutations associated with skin and allergic diseases," The New England Journal of Medicine, vol. 365, no. 14, pp. 1315-1327, 2011.

[29] I.-J. Wang and W. J. J. Karmaus, "The effect of phthalate exposure and filaggrin gene variants on atopic dermatitis," Environmental Research, vol. 136, pp. 213-218, 2015.

[30] H. O. Kim, J. H. Kim, S. I. Cho et al., "Improvement of atopic dermatitis severity after reducing indoor air pollutants," Annals of Dermatology, vol. 25, no. 3, pp. 292-297, 2013.

[31] J. H. Lee, H. S. Lee, M. R. Park et al., "Relationship between indoor air pollutant levels and residential environment in children with atopic dermatitis," Allergy, Asthma and Immunology Research, vol. 6, no. 6, pp. 517-524, 2014. 


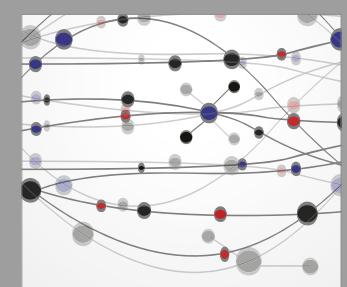

The Scientific World Journal
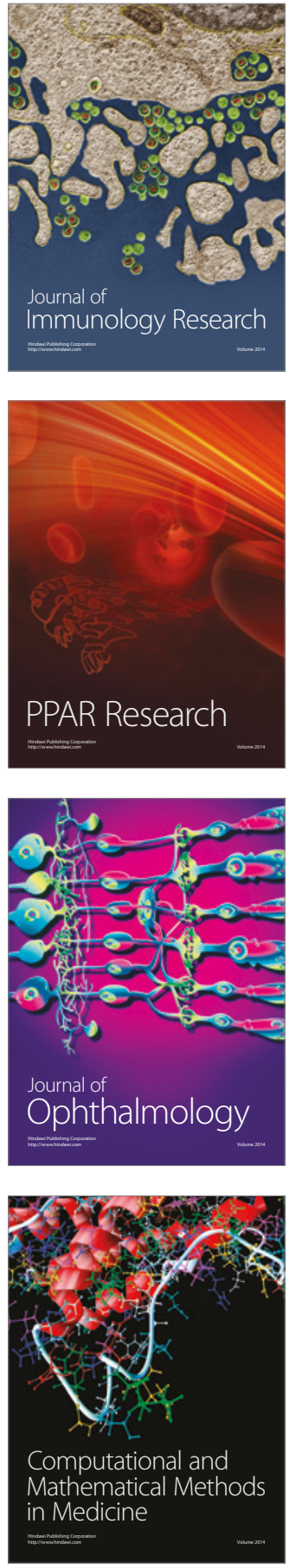

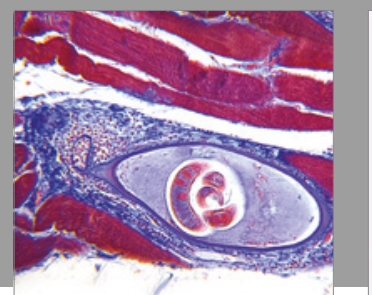

Gastroenterology Research and Practice
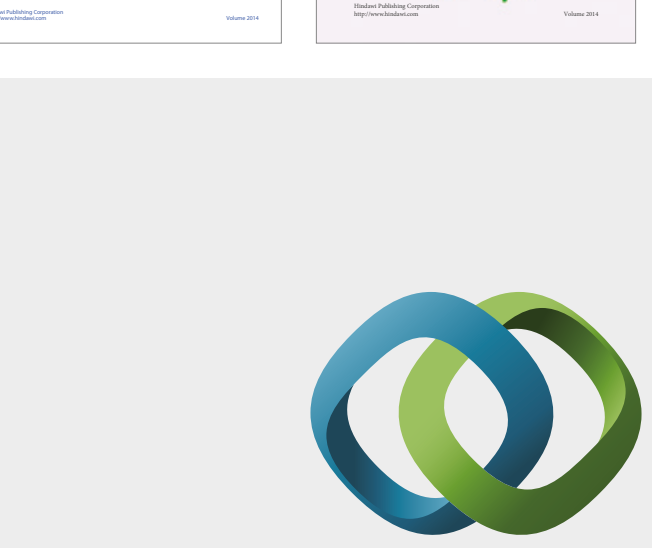

\section{Hindawi}

Submit your manuscripts at

https://www.hindawi.com
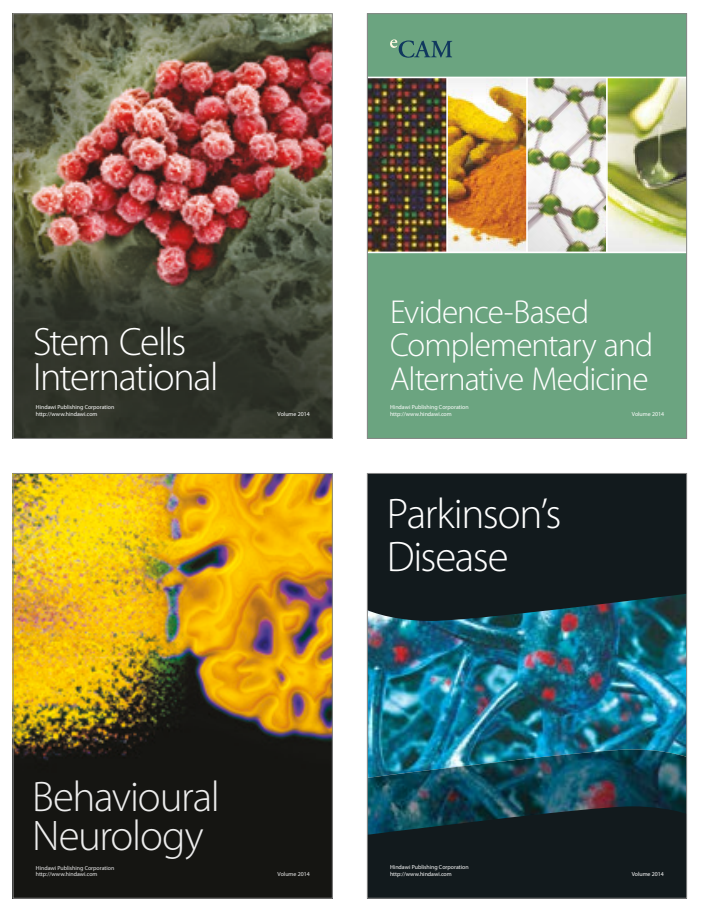
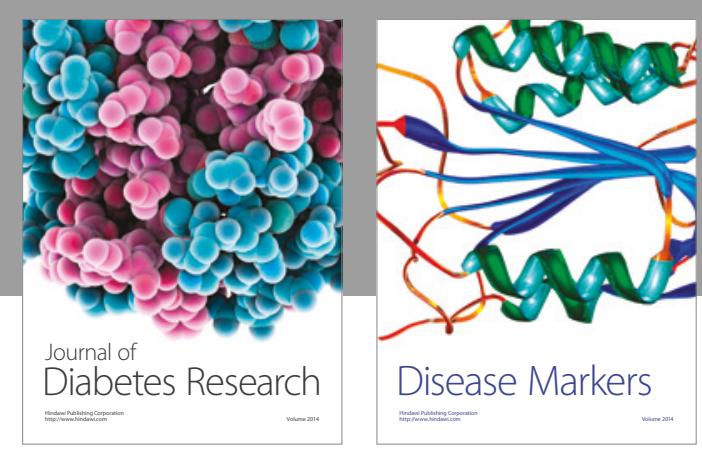

Disease Markers
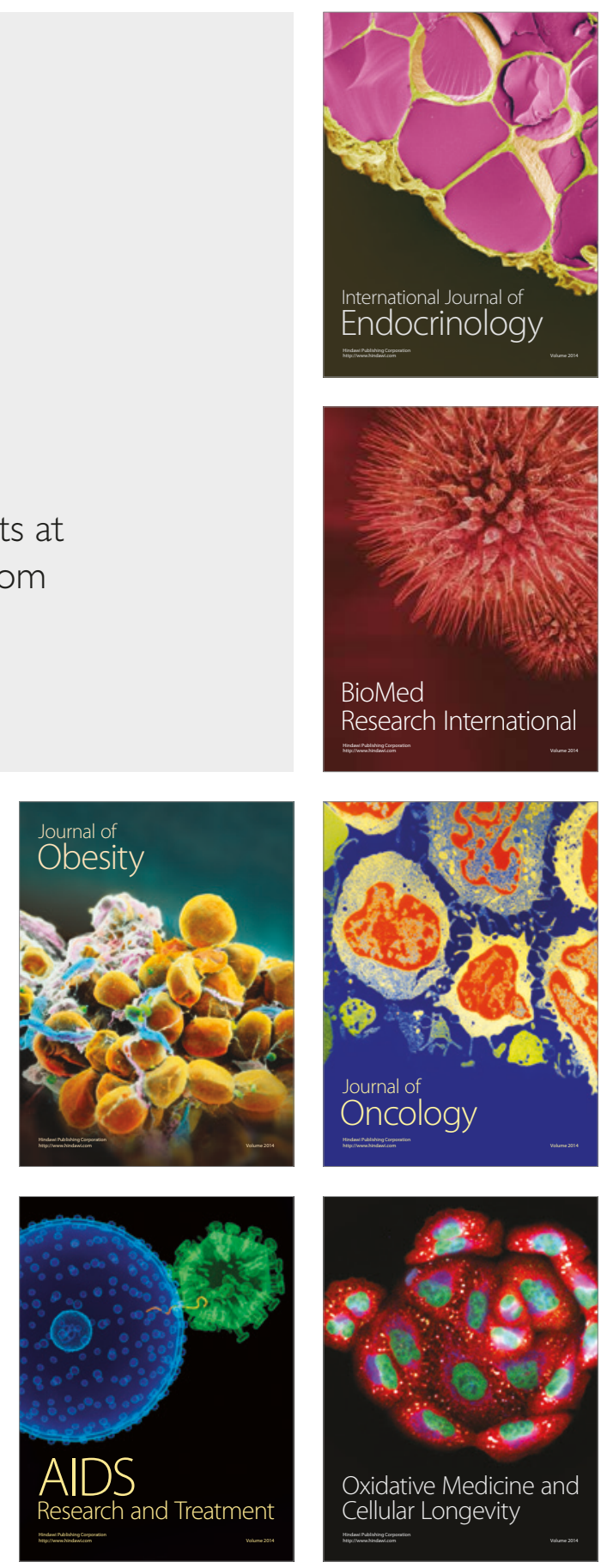